\title{
Construction of Excellent Course Website of Assembly Language Programming
}

\author{
Zhenhua Wang, Fuxiang Gao and Lan Yao \\ College of Information Science and Engineering, Northeastern University, China \\ \{wangzhenhua, gaofuxiang, yaolan\}@ise.neu.edu.cn
}

Keywords: excellent course website, assembly language programming, network teaching

\begin{abstract}
The construction of course website of Assembly Language Programming in Northeastern University is introduced in this paper. The overall thought and main functionality are explained. The design of teaching content, the strategy of interaction and feedback, the strategy of evaluation, and the implementation technology are discussed in detail. The application effect is also given. This website is one of the main parts of Assembly Language Programming, which is named excellent course in Liaoning province of China, and the success of this website promotes the construction of excellent course.
\end{abstract}

\section{Introduction}

Assembly language is the fastest and the most effective language provided for computers. But because it is a low-level language, it is highly dependent on hardware, its instruction set is very tedious, and experiment conditions are very complex. All of these highly enhance the difficulty for learning it [1]. Assembly Language Programming in Northeastern University is one of the excellent courses in Liaoning province of China. Its education mode is that classroom teaching is the basis, course resources such as textbook, courseware and video are the carrier, online questioning, answering and discussion are the auxiliary form, and combined with a variety of evaluation methods, the students are guided to autonomous learning and inquiry learning. We have set up an online teaching platform for this course, and we have constructed a three-dimensional teaching system which integrates classroom teaching and online teaching. The learning effect of students has achieved improvement.

The purpose of this course website is not to replace the traditional classroom teaching, but as an organic complement of the traditional classroom. The course website is the platform of realizing the personalized teaching, and the combination of networked teaching and classroom teaching can take full advantages of both of them [2]. Digital technologies are widely adopted by this website, and especially network technology is adopted to realize course release and information feedback. Construction of excellent course website can increased the teaching diversity, provide the communication space between teachers and students, and also make teachers work more elastic..

\section{Overall Design of Course Website}

\subsection{Design Concept}

Teaching content is the main source of learning information, so it is an important part of the course website. All kinds of teaching contents should be combined organically in the course website. Course website should be able to meet the autonomous learning requirements of students, and students should be able to decide the learning mode and the learning schedule. The navigation system of course website would have to provide the necessary technical support, so navigation system plays an important role in the course website.

Whether the design of interactive strategy in course website reasonable or not will directly affect learning effect of students, so flexible and diverse interaction mode should be provided. The interface should be friendly, simple and clear. The style of interface should be consistent. Through the interface, it should be easy to use the course website. Course website should provide timely feedback 
to make students understand their learning state and improve their learning interests. In the course website, it is very important to provide effective evaluation mechanism to evaluate the study effect of students objectively, scientifically and fairly.

\subsection{Function Modules}

Main functions of this course website are shown in Fig. 1, including user management, content management, homework management, resource management, learning process management, item bank management, BBS management, etc.

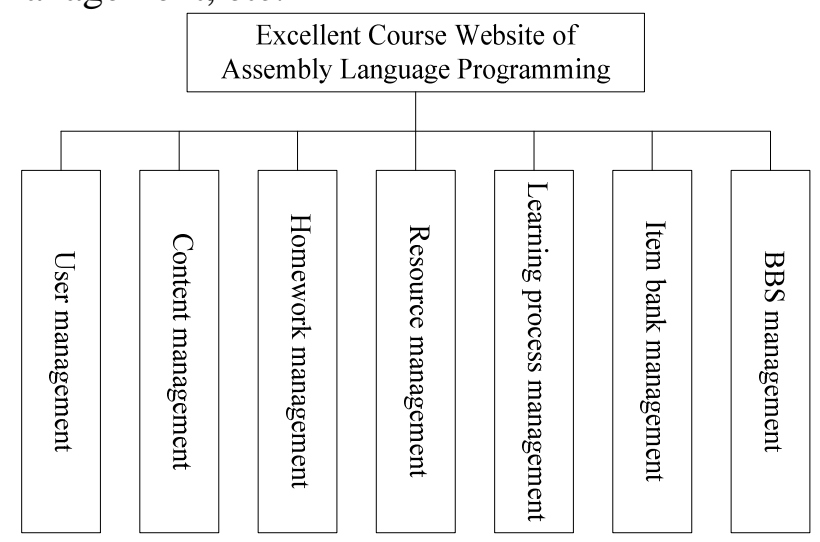

Figure 1 Function Modules of Course Website

\section{Detailed Design of Course Website}

\subsection{Design of Teaching Content}

Online learning is the beneficial complement of classroom teaching. For the students who does not keep up with teaching progress or want to review the content of classroom teaching, they can get online learning guidance, electronic courseware and teaching video, so that the students can continue to learn through the network. The architecture of course resources is shown as Fig. 2, which includes two parts, online learning resources and offline learning resources[3, 4]. The online learning resources are provided by the course website.

\begin{tabular}{|c|c|c|c|c|c|c|c|c|c|}
\hline \multirow{2}{*}{$\begin{array}{c}\begin{array}{c}\text { Online } \\
\text { Answering }\end{array} \\
\begin{array}{c}\text { Records of } \\
\text { answering, } \\
\text { homework, } \\
\text { and discussion }\end{array}\end{array}$} & \multicolumn{2}{|c|}{ Online Browsing and download } & \multirow{2}{*}{$\begin{array}{c}\text { Testing } \\
\begin{array}{c}\text { Item bank and } \\
\text { imitate } \\
\text { examination }\end{array}\end{array}$} & \multicolumn{2}{|c|}{ Video on demand } & \multirow{2}{*}{\multicolumn{2}{|c|}{\begin{tabular}{c|c}
$\begin{array}{c}\text { Hard- } \\
\text { copy }\end{array}$ & $\begin{array}{c}\text { CD/ } \\
\text { DVD }\end{array}$ \\
& \\
Courseware
\end{tabular}}} & & \\
\hline & Courseware & $\begin{array}{c}\text { Electronic } \\
\text { textbook and } \\
\text { experimental } \\
\text { guiding book }\end{array}$ & & $\begin{array}{c}\text { Teaching } \\
\text { video }\end{array}$ & $\begin{array}{c}\text { Multimedia } \\
\text { materials }\end{array}$ & & & $\begin{array}{l}\text { Textbook and } \\
\text { experimental } \\
\text { guiding book }\end{array}$ & $\begin{array}{l}\text { Exercises and } \\
\text { imitate } \\
\text { examination }\end{array}$ \\
\hline \multicolumn{6}{|c|}{ Online learning resources } & \multicolumn{4}{|c|}{ Offline learning resources } \\
\hline \multicolumn{10}{|c|}{ Excellent course of Assembly Language Programming } \\
\hline
\end{tabular}

Figure 2 Architecture of course resources

The entire page layout is rational and plain, and the navigation is detailed and clear. Blue is regarded as the basic color, and color arrangement is harmonious, which can effectively avoid visual fatigue. According to the actual characteristics of course and the learning ability of students, arrange the page content, depth of links, font style, and font size reasonably, and make every page contain moderate amount of information. At one hand, it can satisfy the learning requirements of students, and on the other hand, it will not make students lose interests on learning because of too many contents on page resulted in one-sided pursuit for high information capacity.

We established a dynamic and rich teaching resource repository which has links with related contents, including teaching videos, references, background knowledge, study cases, materials, URLs, and learning tools, etc., to facilitate the learning of students. Adopting modern education technologies, we make electronic lesson plans and multimedia courseware. According to the characteristics of Assembly Language Programming, in the courseware we add a lot of animated 
demos of programs execution, the teaching video and electronic item bank. It makes the students directly obtain the process and results of program execution, and promotes the understanding and absorption. In teaching software, referring to CELTS-17.4.x and ISO/IEC 11172 series of standards, we created and embedded a variety of media to help students to understand the effect of program to memory, stack, register, etc. The media includes the Flash animation, GIF images, MPEG-x video, etc.

Live teaching of the teachers of this course has been captured as video, and it has high reference value for students to learn this course. We provided the teaching video of entire course, so students can systematically watch the video on demand. The practicality of this course is strong, thus we also provided the experiments video.

The selected teaching contents are hierarchically decomposed into a number of knowledge points, in the form of hypertext to layout and organize the teaching content. Students in the networked knowledge system can choose learning content and arrange learning plan freely according to the individual requirements through different kinds of navigation system. The learning process is tracked and recorded. In each chapter of courseware, relevant content resources are provided, so it is convenient for the students to consult. This excellent course website provides the function of online class notes. When the students browse this course, they can write down the improvisational learning content and comments conveniently.

\subsection{Strategy of Interaction and Feedback}

Good interaction and feedback strategy used in the course website can promote the interactive learning and collaborative learning among students, and it is a powerful guarantee to consolidate learning effect. In excellent course website, not only integrated with E-mail, BBS, online testing, chat rooms, and other interactive ways, it is more important to make a reasonable study guidance by interactive control, in order to support student learning better. The students who have questions can get answering through Email of the teacher at any time. The form of BBS is more flexible, the students can leave a message at any time, and the teacher can log in BBS and discuss with students about the problems in the course.

The modules such as online investigation, visit statistics, and message board can make the builder of excellent course website understand the access of visitors and the opinion, satisfaction, advice to this course in a timely manner, thus improvement can be taken. Online BBS can give students a chance to talk over and feed back on the course contents, which is the window for students to discuss and evaluate the curriculum.

\subsection{Evaluation Strategy}

Most of the students think course of Assembly Language Programming is more difficult to learn, it is not easy to understand certain instruction function exactly, and the course itself has strong practicality. According to these characteristics, we adopted the following form and means of learning evaluation.

Self-test after class. Corresponding to each chapter, this website provides some exercises for students to self-test. The types of exercises include completion, multiple choice, program correction, filling in the program, program analysis, debugging programs using DEBUG, etc [5]. After students complete self-testing, the automatic evaluation system will give the standard answer.

Homework. This course web site provides function of homework management, teachers can assign and review the homework in the way of online completely, and students can submit their homework in the way of online completely.

BBS. Students can post messages for discussion on the communication platform of course website. There is at least one teacher to login BBS once a day and to discuss the problems in the course with students. The students can also communicate with each other on this platform.

Experiments support. For the students who want to perform the experiments by themselves, we provide detailed video guidance materials, text guidance materials and samples. So the students can complete the experiments with the help of guidance materials. In the meantime teachers login BBS to guide the students to conduct experiment process. 
Online test. The course website provides an item bank. The teachers can maintain the item bank and add exercises to it. According to the item bank, test paper can be generated automatically, for the use of online test.

\subsection{Key Technologies}

Combining J2EE technology and Oracle $10 \mathrm{~g}$ database system, we developed this dynamic teaching platform which. These two adopted technologies are both the mature technologies, which are able to support system running very well. BBS, questions answering, testing and other interactive platforms provide different permissions to access level, suitable for a variety of identity of users, not only ensuring system security, but also making reasonable function division and avoiding complicated system operation.

\section{Application of Course Website}

Through continuous construction and update, learning support service of this course has achieved to be networked and electronic, greatly improving the efficiency and level of service. This website of online teaching system runs smoothly with short reaction time, and the effectiveness of multimedia part is good. By organizing collective answering, individual answering, experiment guidance, self learning support, etc., students can obtain strong support services on study at the aspects of learning methods, learning contents, emphasis and difficulty. It has won the acceptance of students and teaching administrators. The service satisfaction rate of students is above $95 \%$, and the good study service has promoted the continuous improvement of the teaching and management level.

\section{Summary}

The interactive excellent course website of Assembly Language Programming has improved the teaching effect and teaching efficiency, and it embodies the advantages of networked teaching and brings great convenience to course teaching. Its success has greatly promoted the construction of excellent course of Assembly Language Programming, and it has achieved sharing of the high quality teaching resources in the true sense.

\section{Acknowledgements}

This work is supported by the National Natural Science Foundation of China (61100182) and the Fundamental Research Funds of the Central Universities (N130304002).

\section{References}

[1] Qi, Z. and F. Gao, Assembly Language and Programming. Shenyang: Northeastern University Press, (2005).

[2] Y. Lan, C. Xiuli and L. Miao, et al. Design and Implementation of Web-Based Network Teaching Platform. ETCS, (2009), p. 956-958.

[3] L. Yao, F. Gao and W. Bo. Practice and Research on Tridimensional Teaching Resources Construction of the Course of Computer Networks. IFITA, (2010), p. 406-408.

[4] G. F. A. Y. Dongmei. Research and Practice on Stereoscopic Teaching Resources Construction of the Computer Networks. ICETIS, (2013), p. 381-384.

[5] Jun, Z., Xiuli, C., and Fuxiang, G.: Research on the Practice Teaching of Assembly Language and Programming. IFCSTA, (2009), p. 403-405. 